\title{
A Critique on Present Motor Traffic Act of Sri Lanka Based on a Case Scenario
}

\author{
Ariyarathna HTDW*
}

Department of Forensic Medicine, Faculty of Medical Sciences, University of Sri Jayewardenepura. Sri Lanka.

\begin{abstract}
A young male died following the sinking of his car in a deep lake while driving alone. There had been no indication of a collision. Medical experts determined that the cause of death was drowning. Suicide cannot be ruled out as per the manner of death. This article analyses the Motor Traffic Act in light of this case report and makes a few recommendations to address unforeseen issues. According to the Motor Vehicle Act, this is a "Road traffic accident" in every sense of the word, as well as a fatal accident. The Motor Vehicle Act addresses only pure and simple accidents. If negligence results in a person's death or injury, additional legal provisions, specifically the Penal Code, must be followed to punish the perpetrator. In this case, no collision occurred during this incident, and only one vehicle was involved. The case report discusses the interpretation of the Motor Traffic Act, as it is critical to have a broad understanding of legal issues and law in order to provide an adequate service to other stakeholders such as the judiciary and the Police Department.
\end{abstract}

Keywords: Motor Traffic Act Sri Lanka, collision vs. non-collision, road traffic accidents, road traffic injuries, manner of death

Received: 10 Nov 2021, Revised version accepted: 23 Dec 2021, Published: 31 Dec 2021. *Corresponding author: Ariyarathna HTDW, $\triangle$ Email: ariyaratna@sjp.ac.lk (D) https://orcid.org/0000-0002-4266-5508

Cite this article as: Ariyarathna HTDW. A Critique on Present Motor Traffic Act of Sri Lanka Based on a Case Scenario. Medico-Legal Journal of Sri Lanka, 2021;9(2):25-29. DOI: http://doi.org/10.4038/mljsl.v9i2.7447

Copyright: @ 2019 with the Medico-legal Journal of Sri Lanka.

This is an open-access article distributed under the terms of the Creative Commons Attribution 4.0 International License, which permits unrestricted use, distribution, and reproduction in any medium provided the original author and source are credited.

\section{Introduction}

While transport-related injuries are on the rise in Sri Lanka, they remain a relatively neglected topic in the country, as well as globally.[1,2] In medico-legal death investigation, it is critical to identify the underlying cause/s that initiated the chain of events that directly resulted in the death, as well as any other contributing factors.[3]

In Sri Lanka, the Department of Police is primarily responsible for compiling statistics on transportrelated injuries. In some other countries, transport accident statistics are classified further into collision and non-collision crashes[4] and any kind of injury sustained in connection with a motor vehicle is not considered "Motor Traffic Accidents".

The term "motor traffic injuries" refers to incidents in which a moving vehicle collides with a pedestrian, a stationary object, another vehicle, or when the driver attempts to avoid an accident by turning off the vehicle, etc. What about incidents that result in injury or death while a motor vehicle is stationary and being repaired, or when a vehicle catches fire? Is it reasonable to include them in the category of traffic fatalities? Is it still a road traffic accident under the act if the driver committed suicide (most probably), as in the case presented. The purpose of having road traffic mortality data is to assess a country's current situation and, consequently, to assess national plans and programmes. It will assist in comparing a country's death rate to that of other countries and also in comparing country-specific data. The following case report provides a detailed analysis of the Motor Traffic Act as to what encompasses an accident from medical and legal perspectives.

\section{Case report}

A 27-year-old unmarried male executive, with no abnormal medical or psychiatric history, but with easily irritable and offendable characteristics attended his best friend's birthday party in a hotel. The party was scheduled to begin in the evening and to conclude after lunch on the following day. The unpaved, gravel path leading to the hotel was extremely narrow, barely allowing one vehicle to pass at a time, and ran adjacent to a sizable and deep fresh-water lake (Figure 1). This male and his friends had consumed alcohol during the previous night's party. They had gone to the swimming pool the following morning. The deceased had been bullied by one of his friends while he was in the pool, and he appeared unhappy and angry about it. 
Following that, he abruptly stated to his best friend that he wanted to return home because his mother was waiting for him. As the result, his friend allowed him to leave the hotel before finishing the party.

Neither the deceased's best friend nor any of his other friends had given a second thought about the deceased's safety as he left the party. The friends were well convinced that he was fit to drive home, despite the fact that they had consumed alcohol the night before. He was sober at that point. Later that night, the deceased's best friend received a call from the deceased's mother informing him that her son had not returned home. Following that, the police were notified and immediately began a thorough search for the deceased. Two days after his disappearance, a hotel employee noticed some disturbed grass near the lake approximately 75 metres from the hotel (Figure 1). There had not been any visible brake marks or skid marks. Later, divers discovered the deceased's body in a state of advanced putrefaction inside his car, deep in the lake and somewhat away from the lake bank. No features of a collision were evident.

The postmortem examination revealed that the body had undergone advanced state of putrefaction. The presence of other fatal injuries and natural illnesses that could have been causative or contributory for his death was excluded and thereby the cause of death was formulated as 'Drowning'. The manner of death was left as 'the possibility of suicide cannot be excluded'. His blood alcohol level was inconclusive due to the advanced state of putrefaction. Airbags were not deployed rejecting any substantial frontal collision. The key of the car was within the ignition switch/ lock and it was positioned at the "on" mode. Police investigations confirmed that the victim was not wearing the seatbelt. A CCTV (Closed-Circuit Television) footage was available to indicate the time which he left alone from the hotel. The vehicle had not been produced to the Department of Government Analyst for inspection and if such findings were available it would have been an added value for the investigation.

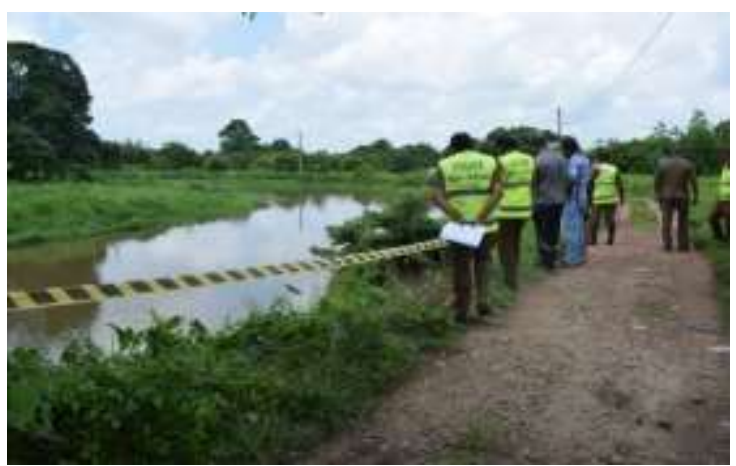

Figure 1: The scene investigation showed disturbed grass indicated with a red arrow leading to the site of sink the deceased with the vehicle.
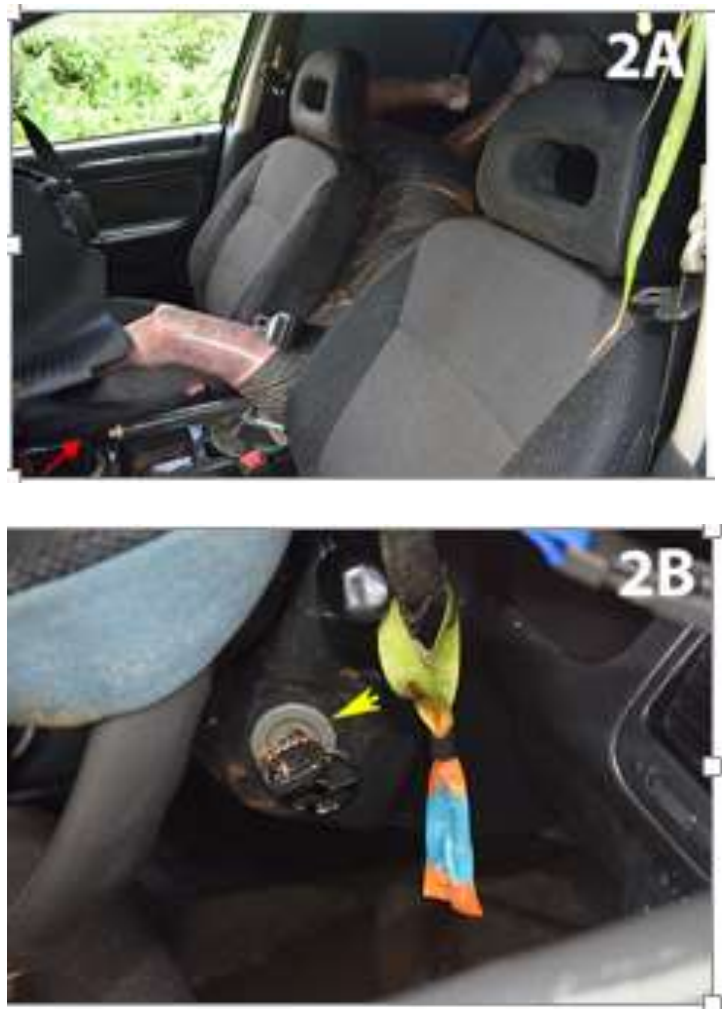

Figure 2A \& 2B: Examination of the vehicle showed the position of the hand-brake (2A) and the ignition switch with a yellow arrow (2B) and it indicated that the vehicle was running at the time of the incident.

\section{Discussion}

To gain a better understanding of the aforementioned case, it is discussed within the context of a preview of the Sri Lankan Motor Traffic Act. Sri Lanka's motor traffic act has been amended several times to reflect the country's development and changing circumstances.[5]

According to the Motor Traffic Act's principal enactment,[6] the term "highway" does not refer to the general highways that the general public refers to. A "highway" is defined as any place over which the public has a right of way or to which the public or any segment of the public has access, as well as any place where motor traffic is regulated by a police officer. Later the definition of "highway was repealed" in the Motor Traffic Act No.08 of 2009 and it was substituted as "road". According to the Act, the road means "the entirety of any public way or any other road to which the public has access and includes a national highway, expressway and restricted access highway and any bridge or culvert over which such road passes".[7] Thus, this case fits the description above. The road on which the 
incident occurred was open to the general public fulfilling the criteria.

In certain countries, traffic accidents have been divided into two broader aspects, traffic accidents Vs non-traffic accidents (crashes). [8] When a person is injured by a vehicle, whilst the person is not directly in traffic or while not driving resulting such incidents are termed as non-traffic injuries.[8,9] In addition to this aspect, when an incident had occurred in private roads or while reversing or with single vehicle accident it is necessary to consider a different nomenclature. A few examples to be mentioned are a failed jack while replacing a tire resulting in injuries and a vehicular fire. There are many possible ways of having injuries by vehicles while not in motion. According to the National Highway Traffic Safety Administration of USA reports that approximately 100,000 injuries occur each year because of non-traffic accidents. According to Australian statistics, such accidents resulted in 12,837 people being hospitalised due to serious injuries in 2003-2004,[10] and 13,639 people being hospitalised during 2006-2007.[11] If such demarcations are included in the Sri Lankan statistics that will present a clear picture.

According to a New Law Report,[12] the driver's vehicle should be under his or her control at the wheel if the driver is to be held accountable for any negligent act caused by the driver of a vehicle, indicating that a driver should have complete control of the steering wheel and vehicle. The victim is the sole occupant and the car was in motion as indicated by the hand brake, and the position of the key in the ignition switch (Figure $3 \mathrm{~A}$ and $3 \mathrm{~B}$ ). At this point, it is worthwhile to illustrate a published case report.[9] A person was killed by a driverless lorry in India. The driver had parked his lorry in a natural downhill without applying the hand brake. At the same time, he was lying down closer to the vehicle resulting in a run over by the same. According to Sri Lankan law, this incident is not an accident since there had not been a person in control of the vehicle or of the steering wheel.[12] Autonomous cars or self-driving cars will be one of the realities soon and accordingly, the law should be adopted.[13]

Given that the case under discussion is a suicide, is it reasonable for the Department of Police to treat this as a fatal accident? The police take the medical opinion into account when determining the manner or circumstances of death. Additionally, police consider the evidence pertaining to and surrounding the case. Unless forensic pathologist provides the Department of Police with accurate information, such incidents may be reported as fatal 'accidents'. This will invariably result in erroneous data. Not only the police department but also the Inquirers into Sudden deaths (ISDs), should have accurate information in order to make an informed decision about the manner of death. There is a widespread misconception among Sri Lankan law enforcement authorities that determining the manner of death is not a forensic pathologist's duty, but rather an ISD's or the judiciary's. However, this is not entirely true, as there are certain areas where no one can provide evidence except a Medical Officer conducting a postmortem. However, when it comes to Indian law, that statement is accurate. In India, an autopsy pathologist is only responsible for determining the cause of death; the manner of death is determined by the police and is generally considered legal.[14] The manner of death is determined in the United States by the death certifier. The Motor Vehicle Act has always taken into account only pure accidental causes, not suicides or homicides.

According to the Motor Traffic Act, an offender who has committed a crime mentioned in the Act would be prosecuted before a magistrate court of Sri Lanka. Anyhow, the prosecution and the judiciary apply the concept of 'strict liability' against the offenders according to the criminal law of the country, in order to maintain the law and order on roads. Pertaining to road traffic offences, usually, the culpability (i.e. 'Mens rea' and 'Actus Reus') is not assessed with equal importance as performed in the other criminal offences under the Penal Code of Sri Lanka. However, gross negligence of the offender or a criminal intention is revealed while committing a crime (incident), the offender shall be prosecuted under much higher grades of crimes under the Penal Code of Sri Lanka as murder or culpable homicide. Therefore reporting the incidents of road traffic accidents under the term "accidents" is not exactly correct. The purpose of the Motor Traffic Act is to ensure public safety while travelling. Retrieving of data is a secondary purpose that is performed by the statisticians in the country to obtain an idea about the countries road traffic incidents. As a result, thorough care should be focused while compiling data to represent the country since all the incidents happening on roads are not accidents.

According to the act, collision is possible resulting in an accident along with another vehicle, animal or object. Anyhow, a sufficient number of 'accidents' can occur without a collision, as demonstrated in this case. In other countries, the first harmful event should be analysed to determine whether a collision occurred or not.[15] In this case, the first harmful event would have been that the vehicle was driven into the lake in order to commit suicide.

The author stipulates that the lack of consensus in the definitions related to the different types of "transportation injuries" may cause practical difficulties. In the Sri Lankan context, police records are the main source of monitoring such injuries. 
However, it is the responsibility of the academics in the health sector to highlight the importance of the subtle differences that exist in the words used at present by the statisticians and even by forensic pathologists. Does the illustrated case in this instant count as an accident? Is it a road traffic collision leading to a fatal incident? The term accident describes an act of random, unexpected, unintended, sudden, unpreventable and uncontrolled event most importantly with nobody's fault. That is why the term road traffic injuries is preferred than the term accident.[15,16] So according to the legal perspectives based on the Motor Traffic Act, the law is only focused on accidents. The Motor Traffic Act expects to prevent unwanted injuries or mishaps while driving and thereby safeguard the public. But in the context of medicine, it is not wise to use the term road traffic accidents, instead, road traffic injuries are preferred as there may be other kinds of injuries by the acts of suicides and homicides.

Time of death and identification were not issues in this case because CCTV evidence (for the time he left the hotel) and his identity card were available. The putrefactive changes were also considered to assess the time since death such as peeling off the skin.

\section{Conclusions}

Traffic laws have been enacted to ensure the safety of society. The Department of Police compiles statistics on road traffic 'accidents' primarily from incidents/traffic violations reported under the Motor Traffic Act. The act is concerned with accidents in their purest form. The traffic law violations are prosecuted at magistrate courts and if the victims wish to obtain compensation they have to go to civil courts in order to recover money as compensation.

Regardless, if an incident does not qualify as a pure and simple accident, it should not be included in the mortality statistics as "fatal accidents," even if it complies with the Motor Traffic Act. Thus, a JMO can assist the police and ISD in determining the nature of an incident when otherwise erroneous data is entered. Finally, COD was stated as 'Drowning' while there was no way to exclude the possibility of suicide as the manner of death.

\section{Disclosure statement}

Conflicts of interest: The author declares that she has no conflicts of interest.

Funding: None

\section{References}

1. Road traffic accidents on the rise [Internet]. Sunday Observer. 2018 [cited 2020 Sep 1]. Available from: http://www.sundayobserver.lk/2018/12/09/news -features/road-traffic-accidents-rise
2. Amarasinghe P.G, Dharmaratne S.D. Epidemiology of road traffic crashes reported in the Kurunegala Police Division in Sri Lanka. Sri Lanka J Med. 2019 Jun 27;28(1):10-9. DOI: http://doi.org/10.4038/sljm.v28i1.102

3. Minino A. International Classification of Diseases Coding and classification of causes of death in accordance with the Tenth Revision of the International Classification of Diseases. [Internet]. Cdc.gov. [cited 7 September 2021]. Available from: https://www.cdc.gov/nchs/ppt/nchs2012/li14_minino.pdf

4. Timmermans C, Alhajyaseen W, Al Mamun A, Wakjira T, Qasem M, Almallah M, et al. Analysis of road traffic crashes in the State of Qatar. Int J Inj Contr Saf Promot. 2019 Sep;26(3):242-50.DOI: 10.1080/17457300.2019.1620289

5. Perera C. Legal aspects of motor traffic trauma in Sri Lanka. Egyptian Journal of Forensic Sciences. 2016;6(4):342-346. https://doi.org/10.1016/j.ejfs.2016.02.001

6. Motor Traffic Act of Sri Lanka, 1979.

7. ACT, No. 08 OF 2009 [Internet]. LawNet. [Cited 7 September 2021]. Available from: https://www.lawnet.gov.lk/act-no-8-of-2009/

8. Golshan K. What is a Non-Traffic Accident? Ingerman \& Horwitz, LLP - Personal Injury Attorneys | Accident, Medical Malpractice, Workers' Comp Attorneys [Internet]. Ingerman \& Horwitz, LLP - Personal Injury Attorneys | Accident, Medical Malpractice, Workers' Comp Attorneys. [cited 8 September 2021]. Available from: https://www.ihlaw.com/blog/what-is-anon-traffic-accident/

9. Das S, Menezes R. Death from a driverless vehicle. Medico-Legal Journal. 2017;86(1):52-4. DOI: $10.1177 / 0025817217741433$

10. Harrison J, Berry J. Serious injury due to transport accidents, Australia, 2005-06 [Internet]. Research @ Flinders. [cited 8 September 2021]. Available from: www.nisu.flinders.edu.au/pubs/reports/2008/inj cat112.pdf

11.Injuries and deaths among children left unattended in or around motor vehicles--United States, July 2000-June 2001 [Internet]. PubMed. [cited 8 September 2021]. Available from: https://www.ncbi.nlm.nih.gov/pubmed/1213918 3

12. A. W. Joachim v L.D. Dharamadasa, 1966 SCS. C. 20/66-M. C. Horana, 37-133. https://www.lawnet.gov.lk/a-w-joachiminspector-of-police-appellant-and-1-ddharmadasa-respondent/

13. 'Self-driving' cars to be allowed on UK roads this year [Internet]. BBC News. 2021 [cited 7 September 2021]. Available from: 
https://www.bbc.co.uk/news/technology56906145

14. Sharma S, Bajpai S. Medicolegal Death Investigation in India: An Overview. Academic Forensic Pathology. 2015;5(3):443-6. https://doi.org/10.23907/2015.048

15.Pérez K, Weijermars W, Bos N, Filtness A.J, Bauer $\mathrm{R}$, Johannsen $\mathrm{H}$, et al. Implications of estimating road traffic serious injuries from hospital data. Accid Anal Prev. 2019 Sep 1;130:125-35.

https://doi.org/10.1016/j.aap.2018.04.005

16. Knechel N. When a crash is really an accident: A concept analysis. J Trauma Nurs Off J Soc Trauma Nurses. 2015;22(6):321-9. doi:10.1097/JTN.0000000000000167 